\title{
Surgical management of organizing pneumonia: a retrospective study of 24 cases in a single Centre
}

Ge Yu, Huaijun Ji* $\mathbb{D}$, Chuizheng Meng, Yixuan Huang, Guogang Gao, Chuanping Liu, Shanlei Wang, Lei Zhang and Jin Ju*

\begin{abstract}
Background: Organizing pneumonia (OP) is a rare disease that is often easily misdiagnosed as a malignancy. The diagnosis of OP can prove quite challenging. Patients typically receive treatment with high-dose corticosteroids. Relapse is common if corticosteroid treatment is reduced or stopped. However, given that long-term corticosteroid treatment often results in significant side-effects, the aim of this study was to discuss the diagnosis and surgical treatment of OP.

Material and methods: The medical records of 24 patients with pathologically diagnosed OP between October 2007 and January 2019 were retrospectively reviewed. All patients underwent thoracic computed tomography (CT) and transbronchial biopsy or CT-guided percutaneous needle aspiration. We analysed the clinical manifestations, radiological findings, diagnostic methods, treatment, and follow-up outcomes of all patients.

Results: In total, 24 patients with OP were identified. The study included 17 (70.8\%) men and 7 (29.2\%) women, and the mean age was $61.25 \pm 11.33$ years (range: $31-82)$. The most common symptom was cough $(n=16 ; 66.6 \%)$, and the most common radiological finding was consolidation $(n=13 ; 54.2 \%)$ on thoracic $C T$. The diagnosis of OP was made by transbronchial biopsy in 11 patients (45.8\%), and percutaneous needle aspiration biopsy in 13 (54.2\%). We performed 11 wedge resections, 9 segmentectomy, and 4 lobectomies. Twenty patients underwent videoassisted thoracoscopic surgery (VATS), and 4 underwent thoracotomy. Complete lesion resection was obtained in all patients, and all patients were discharged from the hospital between 5 and 11 days after surgery. The mean followup period was $59.1 \pm 34.5$ (range: 2-134) months. Residual lesions or local or distant recurrence were not observed.

Conclusions: OP is a rare disease, and the exact aetiology remains unclear. Preoperative diagnosis is difficult to achieve despite the use of transbronchial biopsy or CT-guided percutaneous needle aspiration. Complete surgical resection represents an effective method for the treatment of OP.
\end{abstract}

Keywords: Organizing pneumonia, Surgical management, Corticosteroid treatment

\section{Introduction}

Organizing pneumonia (OP) is a common histopathological response to injury in the lung, demonstrating inflammatory intra-alveolar infiltration that leads to fibrosis on pathology [1]. OP can be primary or secondary to some clinical situations. When OP occurs as a primary entity with an unknown aetiological cause, it is called "cryptogenic OP (COP)". Secondary OP (SOP) is

\footnotetext{
* Correspondence: sdhzcxjhj@sina.com; whxwkjj@sina.com

Department of Thoracic Surgery, Weihai Municipal Hospital, 70 Heping Road, Weihai 264200, Shandong, China
}

associated with various diseases that are known to induce OP, including inflammatory bowel diseases, connective tissue diseases, malignancy, infection, drug reactions, bone marrow or organ transplantation, chemotherapy or radiation therapy for lung or breast cancer, and aspiration [2, 3].

The histopathological pattern of OP typically reveals granulation tissue plugs within the alveoli, alveolar ducts, and small airways (Masson bodies) [2, 4]. These inflammatory tissue plugs occlude the distal bronchioles and previously described bronchiolitis obliterans OP 
(BOOP) [5]. Differential diagnoses include lung cancer, acute and chronic eosinophilic pneumonia, pulmonary lymphoma and pulmonary vasculitis [6, 7]. Corticosteroids represent the main treatment for OP, but relapses are common after reducing or stopping treatment [8-10]. In this retrospective study, we aimed to report the experience on the surgical management of OP patients.

\section{Materials and methods}

The medical records of 24 patients diagnosed with OP from October, 2007 to January, 2019 in our hospital were reviewed. All patients had no history of malignancy, and haven't undergone chemotherapy or radiotherapy. All patients were subject to thoracic computed tomography $(\mathrm{CT})$ scans. Diagnosis of OP was made by transbronchial biopsy or CT-guided percutaneous needle aspiration. The demographic data, symptoms, thorax CT findings, diagnostic methods, and treatments were recorded in all cases. All patients were followed between November 2007 and April 2019. This retrospective study was approved by the Institutional Review Board (IRB) of the Weihai Municipal Hospital, and permission was obtained from all participants.

\section{Statistical analysis}

Only descriptive statistics are provided. In descriptive statistics, frequency and percentages were used for categorical variables, and mean \pm standard deviation values were used for continuous variables. All recorded data statistical analyses were performed using SPSS 20.0 software.

\section{Results}

Between 2007 and 2019, we retrospectively evaluated 24 patients (17 men and 7 women) with a diagnosis of OP. The mean age of the patients was $61.25 \pm 11.33$ years (range: $31-82$ ). The most common symptom was cough, sputum, fever, shortness of breath and chest pain (Table 1).

Blood tests were normal in 15(62.5\%) patients. Increased erythrocyte sedimentation rate (ESR) values were noted in $6(25 \%)$ patients. Increased C-reactive protein values (CRP) were noted in $8(33.3 \%)$ patients, and neutrophilic leucocytosis was noted in $5(20.8 \%)$ patients. Pulmonary function test (PFT) was normal in 20 (83.3\%) of our patients. A restrictive pattern was observed in $2(8.3 \%)$ patients, and an obstructive pattern was determined in $1(4.2 \%)$ patients. The main radiological manifestation was a consolidated, mass-like lesion and ground glass opacity (GGO) (Fig. 1; Table 1). Three lesions were located in the right superior lobar, 2 in the right middle lobe, 7 in the right lower lobe, 4 in the left upper lobe, and 8 in the left lower lobe. The most common lesion location was the bilateral lower lobe (62.5\%). CT scans revealed spicules of margin in 10 (41.7\%) patients, air bronchogram in 7 (29.2\%) patients, significant
Table 1 General characteristics, clinical symptoms, blood tests, pulmonary function test and thoracic $C T$ findings of the patients

\begin{tabular}{|c|c|}
\hline Variables & Results \\
\hline \multicolumn{2}{|l|}{ General Characteristics } \\
\hline Number of patients & 24 \\
\hline Age, years & $61.25 \pm 11.33$ (range: $31-82$ ) \\
\hline Sex (male) & $17(70.8 \%)$ \\
\hline Non-smoker or Ex-smoker & $18(75.0 \%)$ \\
\hline \multicolumn{2}{|l|}{ Clinical Symptoms } \\
\hline Cough & $16(66.6 \%)$ \\
\hline Sputum & $10(41.7 \%)$ \\
\hline Fever & $8(33.3 \%)$ \\
\hline Shortness of breath & $6(25.0 \%)$ \\
\hline Chest pain & $5(20.8 \%)$ \\
\hline Hemoptysis & $3(12.5 \%)$ \\
\hline Weakness & $2(8.3 \%)$ \\
\hline Asymptomatic & $4(16.7 \%)$ \\
\hline \multicolumn{2}{|l|}{ Blood Tests } \\
\hline Elevated CRP & $8(33.3 \%)$ \\
\hline Elevated ESR & $6(25 \%)$ \\
\hline Neutrophilic leukocytosis & $5(20.8 \%)$ \\
\hline Normal & $15(62.5 \%)$ \\
\hline \multicolumn{2}{|l|}{ Pulmonary Function Test } \\
\hline Restrictive pattern & $2(8.3 \%)$ \\
\hline Obstructive pattern & $1(4.2 \%)$ \\
\hline Normal & $20(83.3 \%)$ \\
\hline \multicolumn{2}{|l|}{ Radiological Findings (\%) } \\
\hline Consolidation & $12(50 \%)$ \\
\hline Mass-like lesion & $6(25 \%)$ \\
\hline GGO & $5(20.8 \%)$ \\
\hline Spiculated margin & $10(41.7 \%)$ \\
\hline Air bronchogram & $7(29.2 \%)$ \\
\hline Obvious strengthening & $6(25 \%)$ \\
\hline Lymphadenectasis & $5(20.8 \%)$ \\
\hline Pleural effusion & $3(12.5 \%)$ \\
\hline Pleural indentation & $2(8.3 \%)$ \\
\hline
\end{tabular}

Data are presented as $\mathrm{n}(\%) . C R P$ C-reactive protein, ESR Erythrocyte Sedimentation Rate

enhancement in $6(25 \%)$ patients, lymphadenectasis in 5 (20.8\%) patients, pleural effusion in $3(12.5 \%)$ patients, and pleural indentation in $2(8.3 \%)$ patients. Distant lesions were excluded in all cases.

Transbronchial biopsy was performed in 19 patients, and 14 patients underwent CT-guided percutaneous needle aspiration. Among those, 8 patients experienced one puncture, 2 patients experienced two punctures, 5 patients underwent bronchoscopy once, 4 patients underwent puncture once and bronchoscopy once, 4 

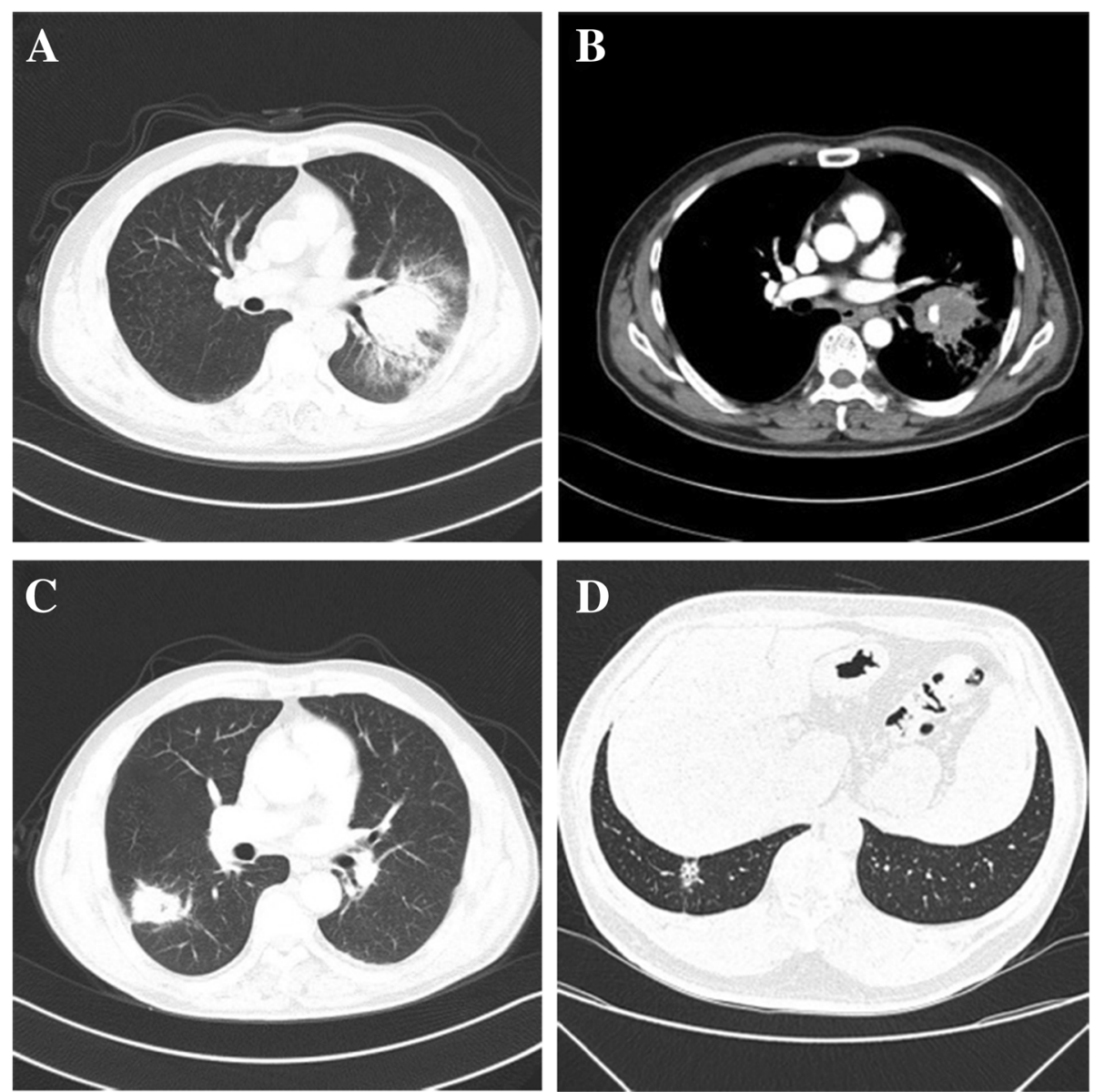

Fig. 1 Thorax CT manifestations of OP cases. $\mathbf{a}$, b OP presenting as a bulky consolidated mass with coarse margins and moderate enhancement in left upper lobe with hilum and mediastinal lymphadenectasis. c OP presenting as a mass-like lesion with coarse margins and pleural indentation, and lowdensity air is noted in the central in the right lower lobe. $\mathbf{d}$ OP presenting as a predominantly ground glass opacity, air bronchogram and pleural indentation in the right lower lobe

patients underwent puncture once and bronchoscopy twice, and 1 patient experienced two punctures and one bronchoscope procedure. The diagnosis of OP was made by transbronchial biopsy in $11(45.8 \%)$ patients, percutaneous needle aspiration in 13 (54.2\%) (Fig. 2).

Three patients were directly treated by surgery due to the family history of lung cancer and malignancy cannot be excluded combined with image data, 7 patients were treated by surgery because they had not responded to treatments for 3-6 months, and 14 cannot tolerate the side effect of steroid. We performed 11 wedge resections, 9 segmentectomy, and 4 lobectomies. Among these procedures, VATS was utilized in 20 cases, and open surgery was utilized in 4 cases. The operation time was $91.36 \pm 43.60(35-210)$ minutes, the blood loss was $83.50 \pm 69.45(20-400) \mathrm{ml}$, the postoperative hospitalization time was $3.67 \pm 1.13$ (3-7) days, and the thoracic tube extubation time was $2.50 \pm 0.92(2-5)$ days (Table 2). Completed lesion resection was obtained in all patients. The postoperative course was uneventful, and patients were discharged from the hospital between 3 and 7 days after surgery.

The mean follow-up period of the patients was $59.1 \pm$ 34.5 months (range 2 to 134 months). There were no obvious discomfort and complication after discharge. One patient was lost to follow-up. Patients are currently still being followed.

\section{Discussion}

$\mathrm{OP}$ is rare. The exact aetiology of this inflammatory reaction remains unclear [11]. OP does not exhibit a sex predilection and is more common in older people, with a mean age of onset of 50-60 years [12]. Rare cases have been reported in children. OP is clearly not related to smoking [10]. Lazor et al. reported that OP is more prevalent in non-smokers or ex-smokers, and the proportion was higher among females [13]. In our study, the mean age of patients was $61.25 \pm 11.33$ (31-82) 

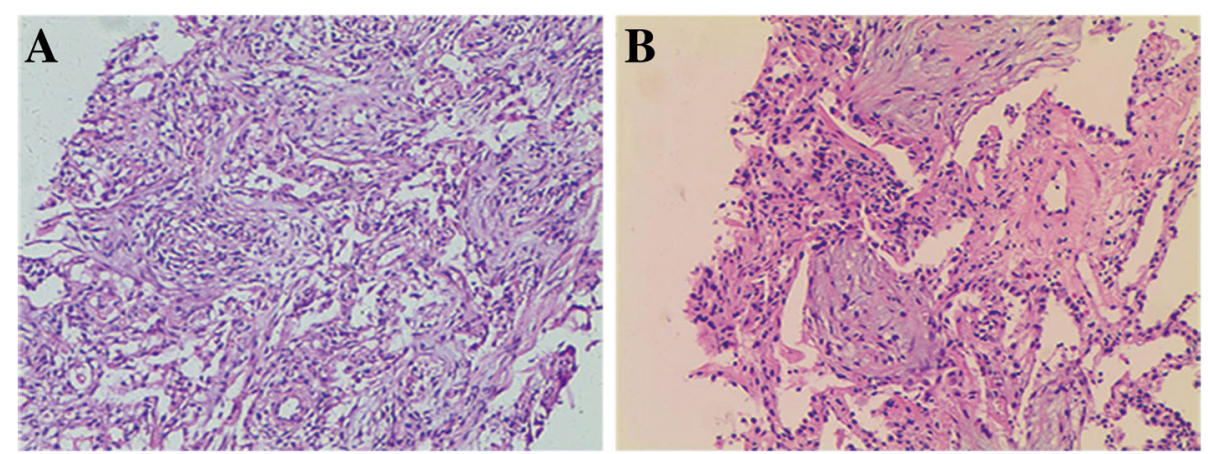

Fig. 2 Histopathological features of OP. a: The structure of lung tissue was destroyed and the alveolar wall tissue was widened. $\mathbf{b}$ : The exudation of fibrin in the alveolar cavity was replaced by granulation tissue. (A: 10× H\&E; B: 40× H\&E)

years, $17(70.8 \%)$ patients were male, and 18 (75.0\%) patients were non-smokers or ex-smokers.

Patients may remain asymptomatic in 30 to $70 \%$ of cases [14]. Common symptoms included cough, dyspnoea, fever, weakness, pleuritic chest pain, weight loss and haemoptysis $[15,16]$. OP is characterized by a mild flu-like illness with nonspecific symptoms [3]. A diagnosis of OP should be considered in patients with a suspected infective pulmonary disorder not responding to antibiotic therapy [17]. In our patients, the most common symptoms included cough, sputum, fever, shortness of breath, and chest pain, haemoptysis, and weakness. Blood tests and pulmonary function test (PFT) do not make a significant contribution to the diagnosis of OP. In the present study, normal blood test in 15(62.5\%) patients, and normal PFT in $20(83.3 \%)$ patients.

There are no specific radiological signs for OP. The most typical imaging pattern of OP is a migratory bilateral patchy alveolar infiltrate [14, 18, 19]. Niksarlıoğlu et al. reported that consolidation was observed in $76.6 \%$ of their cases [12]. Maimon et al. found that consolidation

Table 2 Surgical data of the patients

\begin{tabular}{ll}
\hline Variables & Results \\
\hline scope of surgery & $11(45.8 \%)$ \\
wedge resection & $9(37.5 \%)$ \\
segmentectomy & $4(16.7 \%)$ \\
lobectomies & \\
way of surgery & $20(83.3 \%)$ \\
VATS & $4(16.7 \%)$ \\
open surgery & \\
General Characteristics & $91.36 \pm 43.60(35-210)$ \\
operation time (min) & $83.50 \pm 69.45(20-400)$ \\
blood loss (ml) & $3.67 \pm 1.13(3-7)$ \\
postoperative hospitalization time (d) & $2.50 \pm 0.92(2-5)$ \\
thoracic tube extubation time (d)
\end{tabular}

VATS video-assisted thoracoscopic surgery was present in $77 \%$ of their cases, $86 \%$ had ground glass opacities (GGO), and 32\% had nodules [20]. Similar to the previous studies, consolidation was observed in 12 $(50 \%)$ and mass-like lesions were observed in $6(25 \%)$ of our cases.

Spontaneous remission of OP is rare, therefore, the diagnosis of OP typically requires treatment if the patient is symptomatic [21, 22]. OP exhibits rapid clinical, imaging and functional improvements with corticosteroid treatment. Some cases with mild or recurrent OP have good response treated with macrolide [23]. Series of OP associated with rheumatoid arthritis have described good results when treated with methotrexate, cyclophosphamide and azathioprine [24]. Others series show that tocilizumab could be a therapeutic alternative in refractory OP associated with systemic lupus erythematosus (SLE) [23, 25]. Relapses are common upon corticosteroid dose reduction or treatment suspension, thus often leading to prolonged treatment [26-28]. Recurrence rates vary between 9 and $58 \%[10,12,29]$. However, long-term corticosteroid treatment often results in significant side-effects, such as gastrointestinal bleeding, bone fracture, diabetes mellitus, arterial hypertension, upper respiratory tract infections, urinary tract infections and body weight increase [30, 31]. In our study, 14 patients were treated by surgery because cannot tolerate the side effect of steroid.

OP is often found in the shadows of lung cancer [32, 33]. The coexistence of OP with lung cancer has been reported [34]. Zhao's study of 45 patients with lung cancer concluded that OP lesions may resemble lung carcinoma, and OP may be misdiagnosed as a malignancy [1]. Zhao sought to determine CT features that could differentiate OP from lung carcinoma, however, they concluded that small OP lesions may resemble lung carcinoma [18]. In our study, the main radiological manifestation was consolidated, mass-like lesion and GGO. CT scans revealed lesions with irregular margins $(41.7 \%)$, air bronchogram $(29.2 \%)$, significant enhancement (25\%), lymphadenectasis (20.8\%), pleural 
effusion (12.5\%), and pleural indentation (8.3\%). These features also represent typical manifestations of lung cancer on imaging modalities. Three patients were direct treated by surgery because suspected lung cancer according to the image. After the development of OP, its pathological changes are irreversible, and loss of normal organizational structure and function is observed. The main component of OP is fibrous tissue. Although the lesion size does not initially increase for a short period of time, it will not shrink or be absorbed. Previous studies have indicated that it may lead to scarring or cancer $[35,36]$. So, we think surgery should be performed if the patient cannot tolerate the side effect of steroid or had not responded to treatments.

Complete lesion resection with preservation of uninvolved pulmonary parenchyma remains the fundamental goal in the surgical treatment of OP. If surgical management confirmed, small-range pneumonectomy should be performed, such as segmentectomy or wedge resection, to preserve as much of the functional lung tissue as possible. Hilar lymphadenectomy cannot be recommended as a routine procedure for the treatment of OP. For larger lesions or the mass is located at the hilum, lobectomy can be performed. The frozen pathological sections should be examined during the operation to avoid extending the resection. In our study, 24 patients were treated by surgery. Three patients were treated by surgery because the family history of lung cancer, 7 had not responded to corticosteroid therapy, and 14 cannot tolerate the side effect of steroid. We performed 11 wedge resections, 9 segmentectomy, and 4 lobectomies. We performed 4 lobectomies because those mass is large and close to the hilum of the lung, and wedge resection is very difficult. Among these procedures, VATS was utilized in $20(83.3 \%)$ cases, and the postoperative hospitalization time was $3.67 \pm 1.13$ [3-7] days. We are following them $59.1 \pm 34.5$ months (range 2 to 134 months). There were no obvious discomfort and complication. The prognosis was good in all patients after the operation, and no long-term complications were noted.

\section{Conclusions}

In conclusion, the exact aetiology of OP remains unclear. Hormone therapy should be considered after a clear diagnosis of OP. We can consider surgical treatment when the patient cannot tolerate the side effect of steroid or had not responded to treatments. At surgery, small-range pneumonectomy should be performed and to preserve as much of the functional lung tissue as possible. Complete surgical resection is a safe effective method for the treatment of OP.

\section{Abbreviations}

BOOP: Bronchiolitis obliterans organizing pneumonia; COP: Cryptogenic organizing pneumonia; CRP: C-reactive protein values; CT: Computed tomography; ESR: Erythrocyte sedimentation rate; GGO: Ground glass opacity;
IRB: Institutional Review Board; OP: Organizing pneumonia; PFT: Pulmonary function test; SLE: Systemic lupus erythematosus; SOP: Secondary organizing pneumonia; VATS: Video-assisted thoracoscopic surgery

\section{Acknowledgements}

Not applicable.

\section{Authors' contributions}

Conceived and designed the experiments: GY, JJ. Performed the experiments: HJ. Analyzed the data: CM, YH. Contributed reagents/materials/ analysis tools: GG, CL. Wrote the manuscript: SW, LZ. All authors read and approved the final article.

\section{Funding}

Not applicable.

\section{Availability of data and materials}

Data and materials are available.

\section{Ethics approval and consent to participate}

This retrospective study was approved by the Institutional Review Board (IRB) of the Weihai Municipal Hospital, and permission was obtained from all participants.

\section{Consent for publication}

Not applicable.

\section{Competing interests}

The authors declare that they have no competing interests.

Received: 13 April 2019 Accepted: 17 June 2019

Published online: 28 June 2019

\section{References}

1. Zhao F, Yan SX, Wang GF, Wang J, Lu PX, et al. CT features of focal organizing pneumonia: an analysis of consecutive histopathologically confirmed 45 cases. Eur J Radiol. 2014;83(1):73-8.

2. Shigeyuki N, Ataru N, Yukio I, Tadahiko K, Kengo F, et al. Primary breast lymphoma in the right breast during treatment for left breast cancer. World J Surg Oncol. 2007;5(1):134

3. Dogan D, Ocal N, Yucel O. Cryptogenic organizing pneumonia diagnosed with transbronchial parenchymal biopsy: a case report with accompanying histopathological images. J Turgut Ozal Med Cent. 2016;23(1):81-3.

4. Miao L, Wang Y, Li Y, Ding JJ, Chen LL, et al. Lesion with morphologic feature of organizing pneumonia (OP) in CT-guided lung biopsy samples for diagnosis of bronchiolitis obliterans organizing pneumonia (BOOP): a retrospective study of 134 cases in a single center. J Thorac Dis. 2014;6(9):1251-60.

5. Mueller-Mang C, Grosse C, Schmid K, Stiebellehner L, Bankier AA. What every radiologist should know about idiopathic interstitial pneumonias. Radiographics. 2007;27(3):595-615.

6. Alsaghir AH, Al-Mobeireek AF, Al-Jahdali $\mathrm{H}, \mathrm{Al}$-Eithan A, Al-Otair $\mathrm{H}$, et al. Bronchiolitis obliterans organizing pneumonia: experience at three hospitals in Riyadh. Ann Saudi Med. 2007;27(1):32-5.

7. Ocal N, Dogan D, Ocal R, Tozkoparan E, Deniz O, et al. Effects of radiological extent on neutrophil/lymphocyte ratio in pulmonary sarcoidosis. Eur Rev Med Pharmacol Sci. 2016;20(4):709-14.

8. Basarakodu KR, Aronow WS, Nair CK, Lakkireddy D, Kondur A, et al. Differences in treatment and in outcomes between idiopathic and secondary forms of organizing pneumonia. Am J Ther. 2007;14(14):422-6.

9. Kligerman SJ, Franks TJ, Galvin JR. From the radiologic pathology archives: organization and fibrosis as a response to lung injury in diffuse alveolar damage, organizing pneumonia, and acute fibrinous and organizing pneumonia. Radiographics. 2013;33(7):1951-75.

10. Cordier JF. Cryptogenic organizing pneumonia. Eur Respir J. 2006;28:422-46.

11. Hong G, Kim DH, Kim YS. Successful treatment of acute respiratory failure in a patient with pulmonary Mycobacterium abscessus infection accompanied by organizing pneumonia. J Thorac Dis. 2017;9(6):E560-4.

12. Niksarlıoğlu EY, Özkan GZ, Bakan ND, Yurt S, Kilic L, et al. Cryptogenic organizing pneumonia: clinical and radiological features, treatment outcomes of 17 patients, and review of the literature. Turk J Med Sci. 2016; 46(6):1712-8. 
13. Atsuya $T$, Yuichiro T, Naoko S, Enomoto T, Shinkai M, et al. Clarithromycin mitigates radiation pneumonitis in patients with lung cancer treated with stereotactic body radiotherapy. J Thorac Dis. 2018;10(1):247-61.

14. Drakopanagiotakis F, Paschalaki K, Abu-Hijleh M, Aswad B, Karagianidis N, et al. Cryptogenic and secondary organizing pneumonia: clinical presentation, radiographic findings, treatment response, and prognosis. Chest. 2011; 139(4):893-900.

15. Kebbe J, Abdo T. Interstitial lung disease: the diagnostic role of bronchoscopy. J Thorac Dis. 2017;9(10):S996-S1010.

16. Oymak FS, Demirbas HM, Mavili E, Akgun H, Gulmez I, et al. Bronchiolitis obliterans organizing pneumonia - clinical and roentgenological features in 26 cases. Respiration. 2005;72:254-62.

17. Lisa A, Krista A. Bronchiolitis obliterans organizing pneumonia. Dimens Crit Care Nurs. 2009;28(5):204-8.

18. Long NM, Plodkowski AJ, Schor-Bardach R, Geyer Al, Zheng JT, et al. Computed tomographic appearance of organizing pneumonia in an oncologic patient population. J Comput Assist Tomogr. 2017;41(3):437-41.

19. Travis WD, Costabel U, Hansell DM. An official American Thoracic Society/ European Respiratory Society statement: update of the international multidisciplinary classification of the idiopathic interstitial neumonias. Am Respir Crit Care Med. 2013;188(6):733-48.

20. Maimon N. A 47-year-old female with shortness of breath and "reversed halo sign". Eur Respir Rev. 2010;19(115):83-5.

21. Drakopanagiotakis F, Polychronopoulos V, Judson MA. Organizing pneumonia. Am J Med Sci. 2008;335(1):34-9.

22. Zhan X, Zhang L, Wang Z, Jin ML, Liu M, et al. Reversed halo sign: presents in different pulmonary diseases. PLoS One. 2015;10(6):e0128153.

23. Gimenez AR, Pastrana DB, Huaranga MAR, Izquierdo JR, Cabrera B, et al. Belimumab in refractory organizing pneumonia associated with systemic lupus erythematosus: a case report. LUPUS. 2019;28(4):565-8.

24. Mori S, Koga Y, Sugimoto M. Organizing pneumonia in rheumatoid arthritis patients: a case-based review. Clin Med Insights Circ Respir Pulm Med. 2015; 9(I 1):69-80.

25. Justet A, Ottaviani S, Dieude' P. Tocilizumab for refractory organising pneumonia associated with Sjo" gren's disease. Case Reports. 2015;2015: bcr2014209076.

26. Yoo J-W, Song JW, Jang SJ, Lee CK, Kim MY, et al. Comparison between cryptogenic organizing pneumonia and connective tissue disease-related organizing pneumonia. Rhemumatology. 2011:50(5):932-8.

27. Pathak V, Kuhn JM, Durham C, Funkhouser WK, Henke DC. Macrolide use leads to clinical and radiological improvement in patients with cryptogenic organizing pneumonia. Ann Am Thorac Soc. 2014;11(1):87-91.

28. Cai M, Bonella F, Dai H, Sarria R, Guzman J, et al. Macrolides inhibit cytokine production by alveolar macrophages in bronchiolitis obliterans organizing pneumonia. Immunobiology. 2013;218(6):930-7.

29. Radzikowska E, Wiatr E, Gawryluk D, Renata L, Iwona B, et al. Organizing pneumonia-clarithromycin treatment. Pneumonol Alergol Pol. 2008;76(5):334-9.

30. Radzikowska E, Wiatr E, Langfort R, Bestry I, Skoczylas A, et al. Cryptogenic organizing pneumonia-results of treatment with clarithromycin versus corticosteroids-observational study. PLoS One. 2017;12(9):e0184739.

31. Cazzato S, Zompatorig M, Baruzzi G, Schiattone ML, Burzi M, et al. Bronchiolitis obliterans organizing pneumonia: an Italian experience. Respir Med. 2000;94(7):702-8.

32. Romero S, Barroso E, Rodriguez-Paniagua M, Aranda Fl. Organizing pneumonia adjacent to lung cancer: frequency and clinico-pathologic features. Lung Cancer. 2002;35(2):195-201

33. Casoni GL, Tomassetti S, Cavazza A, Colby TV, Dubini A, et al. Transbronchial lung cryobiopsy in the diagnosis of fibrotic interstitial lung diseases. PLoS One. 2014;9(2):e86716.

34. Song J, Gorgan L, Corkey R, Kwa SLC. An unusual case of bronchiolitis obliterans organizing pneumonia concomitant with bronchioloalveolar carcinoma. Respiration. 2004;71(1):95-7.

35. Chen Y, Yang L, LV J, Ge X, Zhu Q, et al. Diagnosis and surgical treatment of organic pneumonia. Med Inf. 2014;27(3):84-5.

36. Xu D, Zhang J, Yan L, Jiang J. Discussion on the clinical features and surgical indications of organic pneumonia. Tianjin Medical Journal. 1993;7:426-8.

\section{Publisher's Note}

Springer Nature remains neutral with regard to jurisdictional claims in published maps and institutional affiliations.

\section{Ready to submit your research? Choose BMC and benefit from:}

- fast, convenient online submission

- thorough peer review by experienced researchers in your field

- rapid publication on acceptance

- support for research data, including large and complex data types

- gold Open Access which fosters wider collaboration and increased citations

- maximum visibility for your research: over $100 \mathrm{M}$ website views per year

At BMC, research is always in progress.

Learn more biomedcentral.com/submissions 